\title{
Anisotropic Oxygen Reactive Ion Etching for Removing Residual Layers from 45 nm-width Imprint Patterns
}

\author{
Takuya Uehara ${ }^{1}$, Shoichi Kubo ${ }^{2}$, Nobuya Hiroshiba ${ }^{1}$, and Masaru Nakagawa ${ }^{1 *}$ \\ ${ }^{I}$ Institute of Multidisciplinary Research for Advanced Materials (IMRAM), Tohoku University, \\ 2-1-1 Katahira, Aoba-ku, Sendai 980-8577, Japan \\ ${ }^{2}$ National Institute for Materials Science, \\ 1-2-1 Sengen, Tsukuba, Ibaraki 305-0047, Japan
}

\begin{abstract}
We designed and set up an apparatus of oxygen reactive ion etching $\left(\mathrm{O}_{2}\right.$ RIE) with parallel electrode configuration to remove a residual layer located on concave parts of ultraviolet nanoimprinted resist patterns and to maintain the pattern linewidth after dry etching. Imprint resist patterns with $45 \mathrm{~nm}$ line-and-space on a silicon wafer were fabricated with a bisphenol A-based UV-curable resin (NL-KK1) and a fluorinated replica mold under an easily condensable gas atmosphere. Cross-sectional field-emission scanning electron microscope observations revealed that the etching parameters of $\mathrm{O}_{2}$ mass flow rate, $\mathrm{O}_{2}$ pressure, and radio frequency (RF) bias power changed the resist pattern shapes. Steep resist patterns of the hardly changed linewidth could be left without the residual layer on the silicon substrates by tuning the parameters which caused anisotropic $\mathrm{O}_{2}$ RIE. The imprint resist mask was applied for a subsequent dry etching of underneath silicon without any metal hard mask layers, and $45 \mathrm{~nm}$ line-and-space silicon patterns could be obtained.
\end{abstract}

Keywords: oxygen reactive ion etching, UV nanoimprinting, residual layer

\section{Introduction}

Ultraviolet nanoimprint lithography (UV-NIL) [1] has been attractive as a promising lithographic technique to fabricate nanostructure copies in high-throughput and low-cost. The applicability of UV-NIL is widespread to semiconductors $[2,3]$, patterned media [3,4], optical metamaterials [5-7], photonic crystals $[8,9]$, and so forth. In the field of semiconductor devices, the UV-NIL techniques need to downscale steadily sub-50 $\mathrm{nm}$ feature sizes which immersion $\mathrm{ArF}$ photolithography achieved [10].

In a typical lithography process with UV-nanoimprinted resist patterns, dry etching of substrate surfaces is performed after removing a residual layer of resist imprint patterns by oxygen reactive ion etching $\left(\mathrm{O}_{2}\right.$ RIE). During $\mathrm{O}_{2}$ RIE, the linewidth of resist mask need to be maintained to transfer precisely resist pattern shapes to substrate surfaces. Although there are several reports on the achievement of pattern transfer of sub-100 nm structures to substrate surfaces, only the shapes of transferred substrate surfaces are evaluated. The investigation is not focused on shapes of resist patterns after $\mathrm{O}_{2}$ RIE $[11,12]$. A major lithographic process with resist imprint patterns is a method for using a metal or inorganic thin hard mask located between a resist layer and a substrate. High durability of metal or inorganic materials to various reactive ion etching processes enables to fabricate nanostructures with a high aspect ratio [12-18]. The use of a hard mask requires additional steps of depositing a hard mask layer on a substrate surface, etching the hard mask layer with particular gases, and removing patterned hard masks after substrate etching.

A method of cryogenic etching $[19,20]$ is demonstrated for pattern transfer to substrate surfaces. The cryogenic etching at a very low 
temperature results in a decrease of etching rate of resist mask materials. Organic resist layers without a hard mask are available due to improved etching selectivity [21,22]. However, it should be considered that the shrinkage of resist mask materials during cooling has a possibility of increasing defects of resist pattern collapse, because there is a difference in thermal expansion coefficient between resist and substrate materials.

Among various UV-NIL techniques, we notice the bubble-defect-free UV nanoimprinting process performed under an easily condensable gas atmosphere of 1,1,1,3,3-pentafluoropropane (PFP) [23]. The imprint process with PFP has additional advantages of rapid resin filling into mold recesses [24], decreased resin viscosities [25], and low mold pollution [26]. We have recently demonstrated that a bisphenol A-based UV-curable resin, named NL-KK1, showed low mold pollution during UV nanoimprinting and allowed the fabrication of 32-nm-linewidth imprint resist patterns under a PFP atmosphere. In addition, the resist mask without a hard mask was available for dry etching of silicon wafer surfaces by reactive ion etching with a gas mixture of $\mathrm{SF}_{6} / \mathrm{CHF}_{3} / \mathrm{O}_{2}$ [27]. Since the dry etching was performed without removing a residual layer located on concave parts of resist imprint patterns, the linewidth of silicon was decreased to $28 \mathrm{~nm}$ in comparison with the resist linewidth of $32 \mathrm{~nm}$. We further studied the removal of the residual layer using commercially available $\mathrm{O}_{2}$ RIE apparatuses. However, most of dry etchers are designed for fabrication of micro-electro-mechanical sensors (MEMS), and the etching rates of organic resist materials were too large to removal a residual layer of sub-50 nm imprint patterns.

In this study, our research was focused on how to remove a residual layer of the NL-KK1 resist imprint patterns by $\mathrm{O}_{2}$ RIE with the resist linewidth maintained. To observe readily cross-sections of resist imprint patterns on a silicon substrate, we selected a commercially available silica mold of NIM-PHL45 (NTT-AT) containing 45-nm-width line and space patterns. Here, we propose an apparatus of $\mathrm{O}_{2}$ RIE in which electrodes were aligned parallel with a long distance between the electrodes to reduce plasma density and decrease etching rates of resist imprint patterns. We demonstrated anisotropic $\mathrm{O}_{2}$ RIE of 45-nm-wide line and space patterns without changing the linewidth of the resist pattern by tuning etching parameters of an $\mathrm{O}_{2}$ mass flow rate, an $\mathrm{O}_{2}$ pressure, and a $\mathrm{RF}$ bias power.

\section{Experimental}

2.1. $\mathrm{O}_{2}$ RIE apparatus and determination of etching rates

Figure 1 shows the schematic illustration of a main chamber in our developed $\mathrm{O}_{2}$ RIE apparatus.

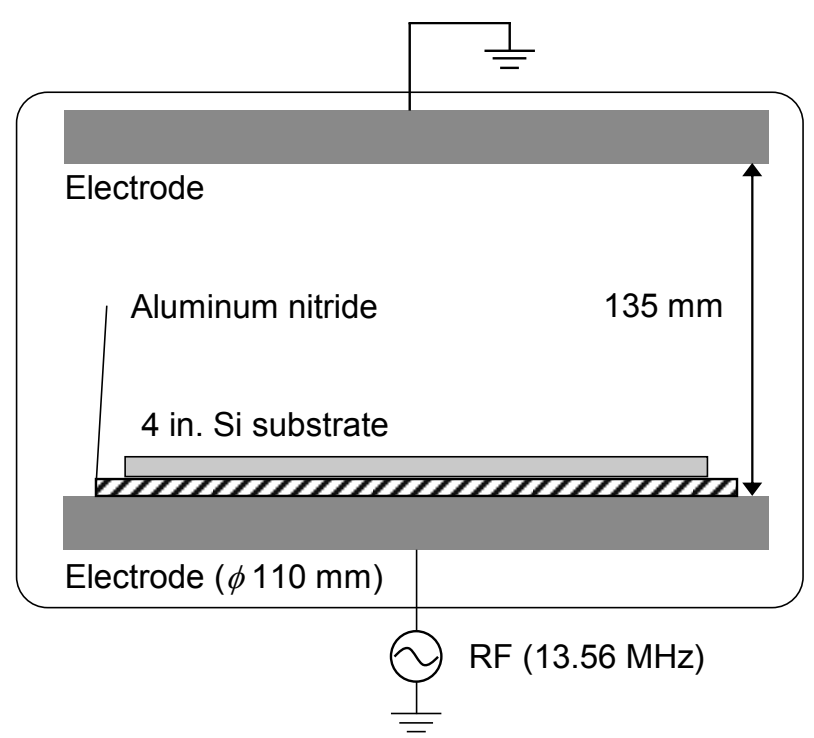

Fig. 1. Schematic illustration of a main chamber of our developed $\mathrm{O}_{2}$ RIE apparatus.

The main chamber was made of stainless SUS304. The inner diameter was $155 \mathrm{~mm}$ and the height was $205 \mathrm{~mm}$. Two electrodes were aligned parallel with a distance of $135 \mathrm{~mm}$ to reduce plasma density. The lower aluminum electrode with a diameter of $110 \mathrm{~mm}$ was connected to a RF generator (Biemtron, RG-300). The RF was set to a constant of $13.56 \mathrm{MHz}$. The RF bias power was changeable up to $100 \mathrm{~W}$. Two mass flow controllers (Kofloc, $8500 \mathrm{MC}$ ) were equipped for $\mathrm{O}_{2}$ and $\mathrm{Ar}$ gas. The $\mathrm{O}_{2}$ pressure in chamber was controlled by operating a butterfly valve set at an outlet. Samples for $\mathrm{O}_{2}$ RIE were loaded on an AlN substrate with $100 \times 100 \mathrm{~mm}^{2}$ and a thickness of $1.0 \mathrm{~mm}$. The temperature of the sample stage was regulated using a water circulator and maintained at $15{ }^{\circ} \mathrm{C}$. The chamber pressure was monitored using a crystal ion gauge (Anelva M-336MX).

A bisphenol A-containing UV-curable resin, named NL-KK1 [27], was used thoroughly in this study. NL-KK1 was composed of a monomer of bisphenol A glycerolate dimethacrylate (BPAGDM, Sigma-Aldrich) and a photoinitiator 2-methyl-1-[4-(methylthio)phenyl]-2-morpholino1-propane (Irgacure 907, BASF Japan). The weight ratio of monomer to photoinitiator was 95:5. NL-KK1 was diluted with a solvent of 
1-methoxy-2-propanol (PGME) for spincoating. The weight ratio of resin to solvent was 1:40. A 4-in. silicon wafer (Matsuzaki Seisakusyo) was cleaned by exposure to vacuum UV light at an emission wavelength of $172 \mathrm{~nm}$ under a pressure of $1.0 \times 10^{3} \mathrm{~Pa}$ for 15 min using a Xe excimer lamp (Ushio, UER-20-172VA). A resin film of approximately $0.1-\mu \mathrm{m}$-thick was prepared on a cleaned silicon wafer by spincoating a diluted NL-KK1 solution and prebaking at $80^{\circ} \mathrm{C}$ for $2 \mathrm{~min}$. The resin film was cured under a nitrogen atmosphere by exposure to UV light for $10 \mathrm{~s}$ at a light intensity of $100 \mathrm{~mW} \mathrm{~cm}$-2 monitored at a detection wavelength of $365 \mathrm{~nm}$. UV light was obtained by emitting from a Hg-Xe lamp (Sanei Electric, Supercure 203s) and passing through a cut-off glass filter $(\lambda>320 \mathrm{~nm})$. The light intensity was monitored using an optical power meter (Hamamatsu Photonics, C-6080-03). The cure resin film was cut into pieces with a square of $15 \times$ $15 \mathrm{~mm}^{2} . \mathrm{O}_{2}$ RIE was carried out under conditions summarized in Table 1. An $\mathrm{O}_{2}$ mass flow rate, an $\mathrm{O}_{2}$ pressure in chamber, and a $\mathrm{RF}$ bias power were changed as experimental parameters. The thicknesses of resin films before and after $\mathrm{O}_{2}$ RIE were measured at a probing force of $10 \mu \mathrm{N}$ using a surface profiler (Kosaka, ET4000A).

Table 1. $\mathrm{O}_{2}$ RIE conditions to etch NL-KK1 resin thin films and remove the residual layer of NL-KK1 imprint resist patterns on Si substrates.

\begin{tabular}{lccccccc}
\hline No. & $\mathbf{1}$ & $\mathbf{2}$ & $\mathbf{3}$ & $\mathbf{4}$ & $\mathbf{5}$ & $\mathbf{6}$ & $\mathbf{7}$ \\
\hline $\begin{array}{c}\mathrm{O}_{2} \text { mass flow } \\
(\mathrm{sccm})\end{array}$ & 5 & 10 & 30 & 10 & 10 & 10 & 10 \\
$\begin{array}{c}\mathrm{O}_{2} \text { pressure } \\
(\mathrm{Pa})\end{array}$ & 0.5 & 0.5 & 0.5 & 0.2 & 1.0 & 0.5 & 0.5 \\
$\begin{array}{c}\mathrm{RF} \text { power } \\
(\mathrm{W})\end{array}$ & 40 & 40 & 40 & 40 & 40 & 20 & 100 \\
\hline
\end{tabular}

2.2. UV nanoimprinting and lithography procedures

A $0.1-\mu \mathrm{m}$-thick spincoated film of NL-KK1 on a 4-in. silicon wafer as mentioned above was subjected to UV nanoimprinting under a PFP atmosphere using a UV nanoimprint stepper (Sanmei, ImpFlex Essential). A replica mold prepared on a $8 \times 8 \mathrm{~mm}^{2}$ silica plate with a UV-curable resin containing glycerol 1,3-diglycerolate diacrylate (Sigma-Aldrich) as a base monomer using a fluorinated silica mold (NTT-AT, NIM-PHL45) was modified with an antisticking agent of tridecaluoro-1,1,2,2tetrahydrooctyltrimethoxysilane (FAS13) by chemical vapor surface modification [28]. The fluorinated replica mold contained 45-nm-wide line and space patterns in $150 \times 450 \mu^{2}$ rectangles. It took approximately $1 \mathrm{~min}$ to perform one shot of the following UV nanoimprinting procedures; (i) bringing the mold surface to the resin film at a speed of $25 \mu \mathrm{m} \mathrm{s}^{-1}$, (ii) increasing applied pressure up to $1.6 \mathrm{MPa}$, (iii) holding the position for load adjustment for $30 \mathrm{~s}$, (iv) curing the molded resin film by exposure to UV light for $10 \mathrm{~s}$ at a $365 \mathrm{~nm}$ light intensity of $100 \mathrm{~mW} \mathrm{~cm}^{-2}$, and (v) demolding at a speed of $4000 \mathrm{~mm} \mathrm{~s}^{-1}$. The imprint resist film was post cured by exposure to UV light at a $365 \mathrm{~nm}$ light intensity of $10 \mathrm{~mW} \mathrm{~cm}^{-2}$ for $10 \mathrm{~s}$ under a nitrogen atmosphere. The silicon wafer with resist imprint pattern was cut into $15 \times$ $15 \mathrm{~mm}^{2}$ square pieces. $\mathrm{O}_{2}$ RIE was carried out under conditions summarized in Table 1. The silicon pieces were cut to obtain cross-sections of imprint resist line patterns. The cross-sectional images were observed using a field-emission scanning electron microscope (FE-SEM, Hitachi S-4800). The linewidths and taper angles of 45-nm-wide line and space resist patterns were analyzed from the FE-SEM images using ImageJ software (National Institute of Health).

A silicon surface with a resist mask after removal of a residual layer by $\mathrm{O}_{2}$ RIE was subjected to dry etching using an inductively coupled plasma (ICP) etcher (Elionix EIS-700). The dry etching was carried out for $40 \mathrm{~s}$ under an ICP power of $300 \mathrm{~W}$, a RF bias power of $100 \mathrm{~W}$, a $\mathrm{SF}_{6}$ flow rate of $5 \mathrm{sccm}$, and $\mathrm{C}_{4} \mathrm{H}_{8}$ flow rate of 10 sccm.

\section{Results and Discussion}

3.1. Design of $\mathrm{O}_{2}$ RIE apparatus and Etching rates

We first thought what is needed for a dry etching system suitable for nanofabrication at sub-100 nm size without complicated techniques and tools. The dry etching apparatus with parallel electrode configuration is one of plasma etchers and used for various reactive ion etching [29]. However, most of dry etchers are designed to achieve larger etching rates than $100 \mathrm{~nm} \mathrm{~min}{ }^{-1}$ and to be applicable for fabrication of MEMS [30,31]. Since the residual layer thickness is generally thinner than $50 \mathrm{~nm}$ in sub-100 $\mathrm{nm}$ resist imprint patterns, the commercially available and widely used dry etchers have etching rates of organic resists too large to control precisely the removal of the thin residual layer. Such large etching rates are realized 
by the use of high-density plasma. The plasma density is controlled by a RF bias power and affected by the distance between electrodes with parallel configuration. In the past decades, the generation and use of high-density plasma is investigated in the field of MEMS and realized by decreasing distance between electrodes. Therefore, we simply went oppositely. That is, low-density plasma will be generated at a long distance between electrodes. In this study, we made the dry etcher with a long distance between electrodes of $135 \mathrm{~mm}$ as shown in Fig. 1.

To assume that we remove anisotropically a residual layer of approximately $50 \mathrm{~nm}$ by $\mathrm{O}_{2}$ RIE, we investigated conditions to realize a low etching rate of several tens nanometers per minute. Figure 2(a) shows changes in film thickness of cured NL-KK1 resin on silicon substrates as a function of etching period. The $\mathrm{O}_{2}$ mass flow rate was changed, while the $\mathrm{O}_{2}$ pressure and the RF bias power were constant to $0.5 \mathrm{~Pa}$ and $40 \mathrm{~W}$, respectively. The film thicknesses decreased linearly to the etching period. The etching rates in $\mathrm{O}_{2}$ RIE were $52 \mathrm{~nm} \mathrm{~min}^{-1}$ for $10 \mathrm{sccm}, 52 \mathrm{~nm} \mathrm{~min}{ }^{-1}$ for $20 \mathrm{sccm}$, and $53 \mathrm{~nm}$ $\mathrm{min}^{-1}$ for $30 \mathrm{sccm}$ in terms of the $\mathrm{O}_{2}$ mass flow rate. It was revealed that the changes in the $\mathrm{O}_{2}$ mass flow rate etching rates hardly had any effects on the etching rates. We investigated whether the $\mathrm{O}_{2}$ pressure in the chamber and the RF bias power showed any effects on the etching rate of cured NK-KK1 films in $\mathrm{O}_{2}$ RIE. Figure 2(b) shows the etching behaviors on varying the $\mathrm{O}_{2}$ pressure under an $\mathrm{O}_{2}$ mass flow rate of $10 \mathrm{sccm}$ and a RF bias power of $40 \mathrm{~W}$, while Fig. 2(c) indicates the etching behaviors on changing the RF bias power under an $\mathrm{O}_{2}$ mass flow rate of $10 \mathrm{sccm}$ and an $\mathrm{O}_{2}$ pressure of $0.5 \mathrm{~Pa}$. A decrease of the film thickness in $\mathrm{O}_{2}$ RIE more rapidly occurred with an increase of $\mathrm{O}_{2}$ pressure and a $\mathrm{RF}$ bias power. In the case of varying $\mathrm{O}_{2}$ pressure, the etching rates were $34 \mathrm{~nm}$ $\min ^{-1}$ for $0.2 \mathrm{~Pa}, 52 \mathrm{~nm} \mathrm{~min}{ }^{-1}$ for $0.5 \mathrm{~Pa}$, and $72 \mathrm{~nm}$ $\min ^{-1}$ for $1.0 \mathrm{~Pa}$. The etching rates were $29 \mathrm{~nm}$ $\min ^{-1}$ for $20 \mathrm{~W}, 52 \mathrm{~nm} \mathrm{~min}{ }^{-1}$ for $40 \mathrm{~W}, 106 \mathrm{~nm}$ $\mathrm{min}^{-1}$ for $100 \mathrm{~W}$ in the case of changing the RF bias power.

No influence of the $\mathrm{O}_{2}$ mass flow rate on the etching rates indicated that the amount of reactive ionized species in $\mathrm{O}_{2}$ RIE was determined by the $\mathrm{O}_{2}$ pressure in the chamber and/or the RF bias power. It was considered that increased concentrations of the reactive ionized species by increasing the $\mathrm{O}_{2}$ pressure resulted in large etching rates in the range of $0.2-1.0 \mathrm{~Pa}$ in terms of the $\mathrm{O}_{2}$ pressure. Since the RF bias power generally affects the amount and acceleration of reactive ionized species, it was though that the increase of the RF bias power generated more reactive ionized species with high energies, which led to large etching rates.
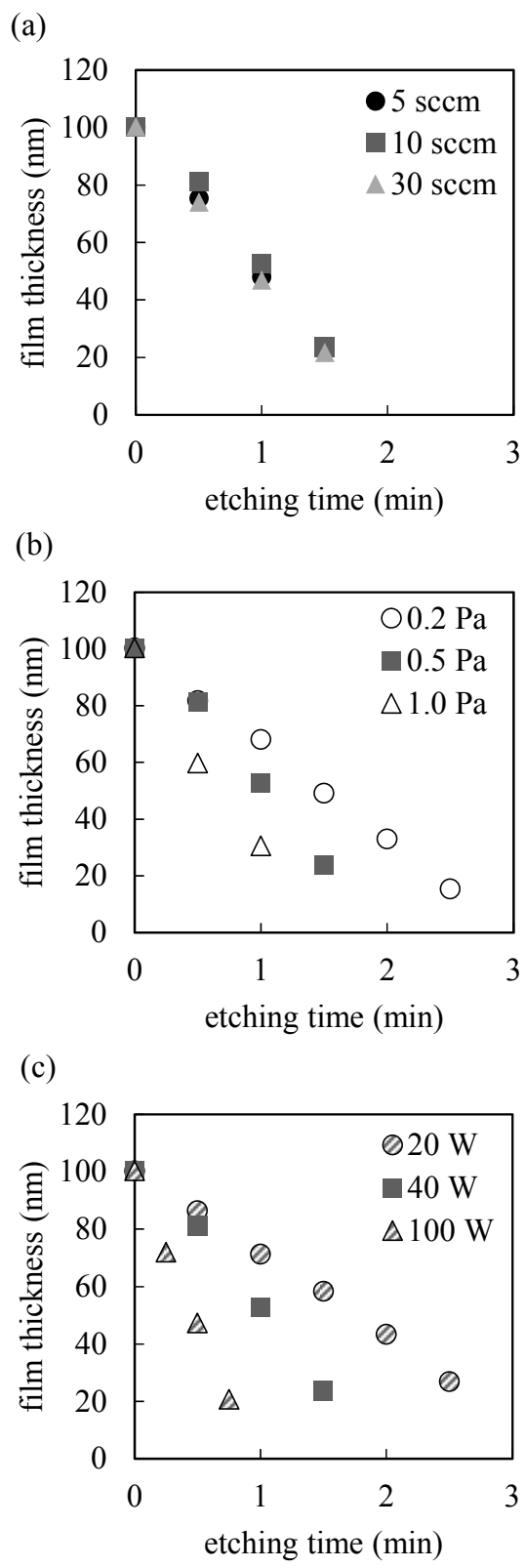

Fig. 2. Changes in thickness of cured NL-KK1 film as a function of $\mathrm{O}_{2}$ RIE period; (a) The $\mathrm{O}_{2}$ mass flow rate varied to 5,10 , and $30 \mathrm{sccm}$ under constant conditions of a $\mathrm{O}_{2}$ pressure of $0.5 \mathrm{~Pa}$ and a RF bias power of $40 \mathrm{~W}$. (b) The $\mathrm{O}_{2}$ pressure varied to $0.2,0.5$, and $1.0 \mathrm{~Pa}$ under an $\mathrm{O}_{2}$ mass flow rate of $10 \mathrm{sccm}$ and a RF bias power of $40 \mathrm{~W}$. (c) The RF bias power varied to 20, 40, and 100 W under an $\mathrm{O}_{2}$ mass flow rate of $10 \mathrm{sccm}$ and an $\mathrm{O}_{2}$ pressure of $0.5 \mathrm{~Pa}$. 


\subsection{Anisotropic $\mathrm{O}_{2}$ RIE to remove selectively a residual layer}

The thickness of a residual layer in NL-KK1 imprint pattern on a silicon substrate was measured to determine the etching period of $\mathrm{O}_{2}$ RIE. Figure 3 shows the cross-sectional FE-SEM image of the imprint pattern. The average linewidth of convex line patterns was $47 \mathrm{~nm}$. The residual layer thickness and the taper angle were $38 \mathrm{~nm}$ and $88^{\circ}$, respectively, in average. Respective etching periods of $\mathrm{O}_{2}$ RIE were simply determined by the residual layer thickness value of $38 \mathrm{~nm}$ divided by the etching rate corresponding to the etching condition summarized in Table I and mentioned in the former section.

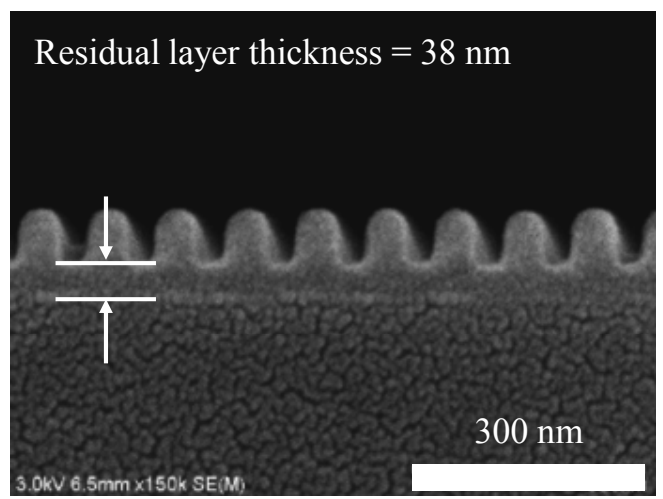

Fig. 3. Cross-sectional FE-SEM image of 45-nm-wide line-and-space NL-KK1 imprint pattern with a residual layer thickness of $38 \mathrm{~nm}$ prepared on a silicon substrate.

Figure 4 shows the cross-sectional FE-SEM images of NL-KK1 imprint patterns after $\mathrm{O}_{2}$ RIE. We confirmed that the residual layer located on concave parts of the imprint patterns were removed completely after $\mathrm{O}_{2}$ RIE. We measured respective linewidths at a bottom of convex line pattern. In the case of varying the $\mathrm{O}_{2}$ mass flow rate, the linewidths of the imprint patterns after $\mathrm{O}_{2}$ RIE were $36 \pm 2 \mathrm{~nm}$ for $5 \mathrm{sccm}$ [Fig. 4(a)], $42 \pm 1 \mathrm{~nm}$ for $10 \mathrm{sccm}$ [Fig. 4(b)], and $47 \pm 1 \mathrm{~nm}$ [Fig. 4(c)] for $30 \mathrm{sccm}$. With increasing the $\mathrm{O}_{2}$ mass flow rate, a decrease of the linewidth after $\mathrm{O}_{2}$ RIE was suppressed. It was indicated that rounded convex line patterns were caused dominantly by isotropic etching in which reactive species had a collision with resist pattern surfaces randomly. The residence time $(\tau)$ is one of the potential factors to cause collision, which is represented by the following equation (1) [32];

$$
\tau=p V / Q
$$

where $p$ is the $\mathrm{O}_{2}$ pressure, $V$ is the chamber volume, and $Q$ is the $\mathrm{O}_{2}$ mass flow rate. A low $\mathrm{O}_{2}$ mass flow rate $(Q)$ has a value of $\tau$ become large.
The large $\tau$ causes a residence time of etched products also to be large, resulting in high possibility of collision with anisotropically directed reactive ionized species. Therefore, the lower $\mathrm{O}_{2}$ mass flow rate was considered to be preferable to anisotropic etching.

Figure 4 (b, d, e) shows the cross-sectional FE-SEM images of NL-KK1 imprint patterns after $\mathrm{O}_{2}$ RIE under conditions of varying the $\mathrm{O}_{2}$ pressure with an $\mathrm{O}_{2}$ mass flow rate of $10 \mathrm{sccm}$ and a RF bias power of $40 \mathrm{~W}$. The change in the $\mathrm{O}_{2}$ pressure hardly affected the linewidths of imprint patterns, which were slightly decreased to approximately 42 $\mathrm{nm}$. In contrast, the taper angles of the imprint line patterns were changed by the $\mathrm{O}_{2}$ pressure in the chamber. The taper angles were $86^{\circ}$ for $0.2 \mathrm{~Pa}$ [Fig. 4(d)], $79^{\circ}$ for $0.5 \mathrm{~Pa}$ [Fig. 4(b)], and $79^{\circ}$ for $1.0 \mathrm{~Pa}$ [Fig. 4(e)]. The low $\mathrm{O}_{2}$ pressure of $0.2 \mathrm{~Pa}$ suppressed a decrease of taper angle. The mean free path (MEP) of reactive ionized species is one of the important factors to determine anisotropy in dry etching. MEP means the distance until which a reactive species has a collision with another reactive species. MEP is represented by the following equation (2) [32];

$$
\mathrm{MFP}=1 / n \sigma=k T / p \sigma
$$

where $n$ is the plasma density, $\sigma$ is the intrinsic cross-sectional area of active species, $k$ is the Boltzmann constant, $T$ is the temperature of plasma, and $p$ is the $\mathrm{O}_{2}$ pressure under a constant volume of an etching chamber. Therefore, it was considered that the $\mathrm{O}_{2}$ pressure of $0.2 \mathrm{~Pa}$ had a mean free path of reactive ionized species increased and etching occur anisotropically.

Finally, we investigated whether the RF bias power influence on the changes in linewidth and taper angle of the NL-KK1 imprint patterns. The $\mathrm{RF}$ bias power varied in the range of $20-100 \mathrm{~W}$, while the $\mathrm{O}_{2}$ mass flow rate and $\mathrm{O}_{2}$ pressure were constant to $10 \mathrm{sccm}$ and $0.5 \mathrm{~Pa}$, respectively. The linewidths were hardly affected by the RF bias power, while the taper angles were remarkably decreased with increasing the RF bias power. The taper angles were $88^{\circ}$ for $20 \mathrm{~W}$ [Fig. $4($ f) $], 79^{\circ}$ for $40 \mathrm{~W}$ [Fig. 4(b)], and $75^{\circ}$ for $100 \mathrm{~W}$ [Fig. 4(g)]. The high RF power increases a plasma density, and the increased plasma density resulted in lowering MFP of reactive ionized species. On the other hand, the anisotropy of etching is promoted because the high RF power accelerates ionized species. In our developed $\mathrm{O}_{2}$ RIE apparatus, the low RF bias power of $20 \mathrm{~W}$ causing a low plasma density $(n)$ was preferable for the anisotropy of etching. 

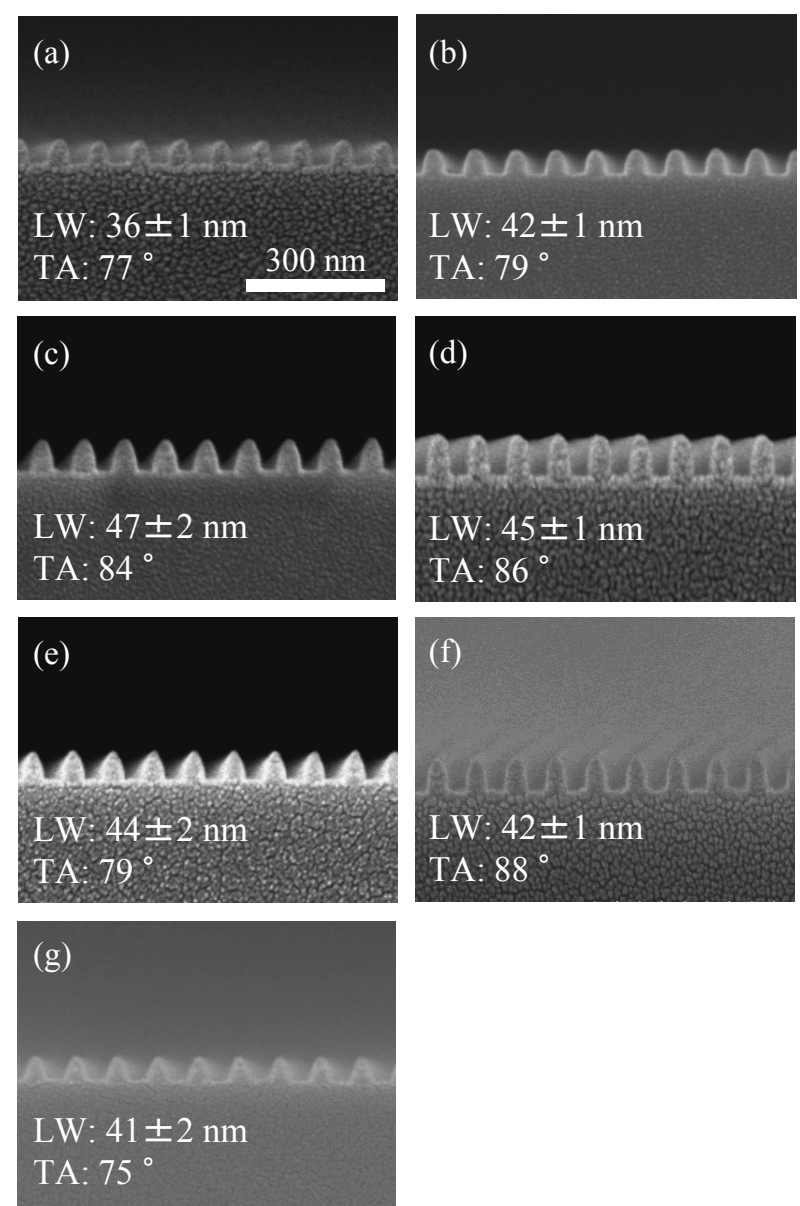

Fig. 4. Cross-sectional FE-SEM images of 45-nm-wide line-and-space NL-KK1 imprint patterns after $\mathrm{O}_{2}$ RIE under conditions [etching period, $\mathrm{O}_{2}$ flow rate, $\mathrm{O}_{2}$ pressure, RF bias power]; (a) [50 s, $5 \mathrm{sccm}, 0.5 \mathrm{~Pa}, 40$ W], (b) [50 s, $10 \mathrm{sccm}, 0.5 \mathrm{~Pa}, 40 \mathrm{~W}]$, (c) [49 s, $30 \mathrm{sccm}$, $0.5 \mathrm{~Pa}, 40 \mathrm{~W}$, (d) [76 s, $10 \mathrm{sccm}, 0.2 \mathrm{~Pa}, 40 \mathrm{~W}$, (e) [36 s, $10 \mathrm{sccm}, 1.0 \mathrm{~Pa}, 40 \mathrm{w}]$, (f) [89 s, $10 \mathrm{sccm}, 0.5 \mathrm{~Pa}, 20$ $\mathrm{W}]$, and (g) [25s, $10 \mathrm{sccm}, 0.5 \mathrm{~Pa}, 100 \mathrm{~W}]$. The abbreviations of LW and TA insert in the images mean linewidth and taper angle, respectively.

In summary, we determined the conditions of $\mathrm{O}_{2}$ RIE carried out at an $\mathrm{O}_{2}$ mass flow rate of 10 sccm, an $\mathrm{O}_{2}$ pressure of $0.2 \mathrm{~Pa}$, a RF bias power of $40 \mathrm{~W}$, and an etching period of $76 \mathrm{~s}$. We further investigated the pattern transfer of the NL-KK1 imprint pattern after removal of the residual layer to a silicon substrate surface. Figure 5 shows the cross-sectional FE-SEM image of a silicon substrate surface after ICP etching with a gas mixture of $\mathrm{SF}_{6}$ and $\mathrm{C}_{4} \mathrm{H}_{8}$. Using the resist mask with a linewidth of $45 \mathrm{~nm}$, we could fabricate 45-nm-wide silicon patterns. We confirmed that the UV-curable resin of NL-KK1 was available for UV nanoimprint lithography of silicon surfaces through anisotropic $\mathrm{O}_{2}$ RIE and ICP etching.

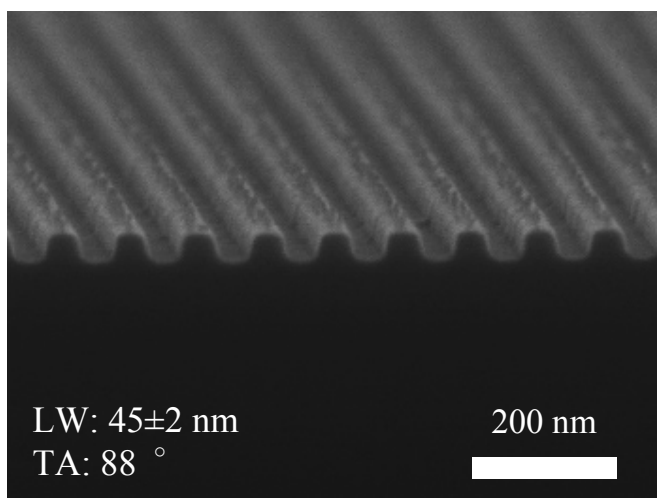

Fig. 5. Cross-sectional SEM image of silicon line-and-space pattern fabricated by dry etching using a 45-nm-wide NL-KK1 resist mask after removal of a residual layer by $\mathrm{O}_{2}$ RIE under conditions of an etching period of $76 \mathrm{~s}$, an $\mathrm{O}_{2}$ flow rate of 10 , an $\mathrm{O}_{2}$ pressure of 0.2 , and a $\mathrm{RF}$ bias power of $40 \mathrm{~W}$. The abbreviations of $\mathrm{LW}$ and TA insert in the image mean linewidth and taper angle, respectively.

\section{Conclusion}

We designed and demonstrated the dry etching apparatus for $\mathrm{O}_{2}$ RIE that is one process of UV nanoimprint lithography. The configuration of electrodes was parallel with a distance of $135 \mathrm{~mm}$ to intend to reduce a plasma density. The etching rates were controllable at several tens nanometers by turning the parameters of an $\mathrm{O}_{2}$ mass flow rate, an $\mathrm{O}_{2}$ pressure, and a RF bias power. The imprint resist patterns with a linewidth of $45 \mathrm{~nm}$ and a residual layer thickness of $38 \mathrm{~nm}$ made from the NL-KK1 UV-curable resin could be etched anisotropically under an $\mathrm{O}_{2}$ mass flow rate of 10 $\mathrm{sccm}$, an $\mathrm{O}_{2}$ pressure of $0.2 \mathrm{~Pa}$, a RF bias power of $40 \mathrm{~W}$, and an etching period of $76 \mathrm{~s}$. The residual layer was removed with the resist linewidth maintained after $\mathrm{O}_{2}$ RIE. The systematic study by cross-sectional FE-SEM observations of the resist patterns on silicon substrate surfaces after $\mathrm{O}_{2}$ RIE suggested that the residence time $(\tau)$ and mean free path (MFP) of reactive ionized species had significant effects on the linewidth and taper angle of the resist pattern, respectively. Silicon trench patterns with a linewidth of $45 \mathrm{~nm}$ were successfully obtained by UV nanoimprint lithography without any metal or inorganic hard masks. The silicon trench will be available for directed self-assembly of polystyrene-block-poly(methyl methacrylate) and other block copolymers and for block copolymer lithography to achieve sub-20 nm patterning. 


\section{Acknowledgments}

The authors would like to thank Mr. Yuta Seino (Elionix) for the support of Si dry etching. This work was supported in part by KAKENHI (\#15J05451, \#15H03860) from MEXT of Japan.

\section{References}

1. J. Haisma, M. Verheijen, K. van den Heuvel, and J. van den Berg, J. Vac. Sci. Technol. B, 14 (1996) 4124. doi: 10.1116/1.588604T.

2. K. Selinidis, E. Thompson, G. Schmid, N. Stacey, J. Perez, J. Maltabes, D. J. Resnick, J. Yeo, H. Kim, and B. Eynon, Proc. SPIE, 7028 (2008) 70280R. doi: 10.1117/12.793034

3. Z. Ye, R. Ramos, C. B. Brooks, P. Hellebrekers, S. Carden, and D. La Brake, Proc. SPIE, 7637 (2010) 76371A. doi: $10.1117 / 12.849226 \mathrm{~T}$.

4. G. M. Schmid, C. Brooks, Z. Ye, S. Johnson, D. La Brake, S. V. Sreenivasan, and D. J. Resnick, Proc. SPIE, $\mathbf{7 4 8 8}$ (2009) 748820. doi: 10.1117/12.833366T.

5. I. Bergmair, M. Mühlberger, K. Hingerl, E. Pshenay-Severin, T. Pertsch, E. B. Kley, H. Schmidt, and R. Schöftner, Microelectron. Eng., 87 (2010) 1008. doi: 10.1016/j.mee.2009.11.109

6. T. Uehara, T. Tomioka, S. Kubo, M. Hoga, and M. Nakagawa, Chem. Lett., 42 (2013) 1475. doi: 10.1246/cl.130720

7. T. Uehara, S. Kubo, and M. Nakagawa, Jpn. J. Appl. Phys., 54 (2015) 06FM02. doi: $10.7567 / J J A P .54 .06 F M 02 R$.

8. K. Ishihara, M. Fujita, I. Matsubara, T. Asano, and S. Noda, Jpn. J. Appl. Phys., 45 (2006) L210. doi: 10.1143/JJAP.45.L210T.

9. K. Ishihara, M. Fujita, I. Matsubara, T. Asano, S. Noda, H. Ohata, A. Hirasawa, H. Nakada, and N. Shimoji, Appl. Phys. Lett., 90 (2007) $111114 . \quad$ doi: $10.1063 / 1.2713237 \mathrm{H}$.

10. J. L. Sturtevant, D. V. Steenwinckel, H. Kwinten, S. Locorotondo, and S. Beckx, Proc. SPIE, 5376 (2004) 215. Doi: $10.1117 / 12.53269539 \mathrm{H}$.

11. H. Schmitt, B, Amon, S. Beuer, S. Petersen, M. Rommel, A. J. Bauer, and H. Ryssel, Microelectron. Eng., 86 (2009) 636. doi: 10.1016/j.mee.2008.11.01745

12. J. Chen, J. Shi, A. Cattoni, D. Decanini, Z. Liu, Y. Chen, and A. M.
Hanghiri-Gosnet, Microelectron. Eng., 87 (2010) $899 . \quad$ doi: 10.1016/j.mee.2009.12.01246

13. P. Mukherjee, M. G. Kang, T. H. Zurbuchen, L. J. Guo, and F. A. Herrero, J. Vac. Sci. Technol. B, 25 (2007) 2645. doi: 10.1116/1.280461247

14. L. Sainiemi, J. Viherial, T. Sikanen, J. Laukkanen, and T. Niemi, J. Micromech. Microeng., 20 (2010) 077001. doi: 10.1088/0960-1317/20/7/077001.

15.X. Guo, J. Hu, Z. Zhuang, M. Deng, F. Wu, X. Li, B. Liu, C. Yuan, H. Ge, F. Li, and Y. Chen, J. Vac. Sci. Technol. B 32 (2014) 06FG06. doi: 10.1116/1.4898778

16. C. Acikgoz, B. Vratzov, M. A. Hempenius, G. J. Vancso, and J. Huskens ACS Appl. Mater. Inter. 1 (2009) 2645. doi: 10.1021/am9005379L.

17. Y. Tsuji, M. Yanagisawa, H. Yoshinaga, and K. Hiratsuka, J. Phys.: Conf. Ser., 191 (2009) 012010 . doi:10.1088/1742-6596/191/1/012010

18. Y. Tsuji, M. Yanagisawa, H. Yoshinaga, N. Inoue, and T. Nomaguchi, Jpn. J. Appl. Phys. 50 (2011) 06GK06. doi: 10.1143/JJAP.50.06GK06

19. S. Tachi, K. Tsujimoto, and S. Okudaira, Appl. Phys. Lett. 52 (1988) 616. doi: 10.1063/1.99382

20. R. Dussart, T. Tillocher, P. Lefaucheux, and M. Boufnichel, J. Phys. D: Appl. Phys., 47 (2014) 123001. doi: 10.1088/0022-3727/47/12/123001

21. Y. Wu, D. L. Olynick, A. Goodyear, C. Peroz, S. Dhuey, X. Liang, and S. Cabrini, Microelectron. Eng., 88 (2011) 2785. doi: 10.1016/j.mee.2010.11.055

22. Z. Liu, Y. Wu, B. Harteneck, and D. Olynick, Nanotechnology, 24 (2013) $015305 . \quad$ doi: 10.1088/0957-4484/24/1/015305

23. H. Hiroshima and M. Komuro, Jpn. J. Appl. Phys., 46 (2007) 6391. doi: 10.1143/JJAP.46.6391

24. H. Hiroshima, Jpn. J. Appl. Phys., 47 (2008) 5151. doi: 10.1143/JJAP.47.5151

25. H. Hiroshima, H. Atobe, and Q. Wang, J. Photopolym. Sci. Technol., 23 (2010) 45. doi: 10.2494/photopolymer.23.45

26. K. Kobayashi, S. Kubo, H. Hiroshima, S. Matsui, and M. Nakagawa, Jpn. J. Appl. Phys., 50 (2011) 06GK02. doi: 
10.1143/JJAP.50.06GK02

27. M. Nakagawa, K. Kobayashi, A. Hattori, S. Ito, N. Hiroshiba, S. Kubo, and $\mathrm{H}$. Tanaka, Langmuir, 31 (2015) 4188. doi: 10.1021/acs.langmuir.5b00325

28. A. Kohno, N. Sakai, S. Matsui, and M. Nakagawa, Jpn. J. Appl. Phys., 49 (2010) 06GL12. doi: 10.1143/JJAP.49.06GL 1257

29. J. A. Bondur, J. Vac. Sci. Technol., 13 (1976) 1023. doi: 10.1116/1.569054

30. R. Legtenberg, H. Jansen, M. D. Boer, and
M. Elwenspoek, J. Electrochem. Soc., 142 (1995) 2020. doi: 10.1149/1.2044234

31. M. Sekine, Appl. Surf. Sci., 192 (2002) 270.

doi:

10.1016/S0169-4332(02)00031-4

32. T. Tatsumi, H. Hayashi, S. Morishita, S. Noda, M. Okigawa, N. Itabashi, Y. Hikosaka, and M. Inoue, Jpn. J. Appl. Phys., $37 \quad$ (1998) 2394. doi: $10.1143 /$ jjap.37.239461 